\title{
Validation of terrestrial water storage change estimates using hydrologic simulation
}

\author{
Sang-Il Lee', Jae Young Seo ${ }^{1}$, Sang Ki Lee ${ }^{2}$ \\ ${ }^{1}$ Department of Civil and Environmental Engineering, Dongguk University, Seoul, South Korea \\ ${ }^{2}$ Department of Civil Engineering, University of Idaho, Boise, ID, USA
}

\section{Email address:}

islee@dongguk.edu (S. -I. Lee), dabbi2011@naver.com (J. Y. Seo), sklee81@hotmail.com (S. K. Lee)

\section{To cite this article:}

Sang-Il Lee, Jae Young Seo, Sang Ki Lee. Validation of Terrestrial Water Storage Change Estimates Using Hydrologic Simulation. Journal of Water Resources and Ocean Science. Vol. 3, No. 1, 2014, pp. 5-9. doi: 10.11648/j.wros.20140301.12

\begin{abstract}
New methods estimating the amount of water storage on Earth have evolved over the years. One of them utilizes the gravitational field variation observed from the GRACE satellite. Compared to conventional methods such as water balance analysis, the method makes it simple and straightforward to obtain the terrestrial water storage change (TWSC). Previous studies show that there is a discrepancy between GRACE-based and water balance-based estimates especially in wet periods. Along with precipitation and evapotranspiration, it is common that runoff data needed for the water balance analysis are obtained from GLDAS (Global Land Data Assimilation System). In this study, GLDAS runoff data are replaced with hydrologic simulation results with such anticipation that local geomorphologic and hydrologic characteristics can be better incorporated. In an application to a relatively small basin during a wet period, GLDAS- and simulation-based TWSCs showed values 2.73 3.58 times higher than the GRACE-based estimate. It implies that the GRACE-approach underestimates TWSC during wet periods. It also suggests the need for correction factors to adjust the GRACE-based estimates in the rainy season.
\end{abstract}

Keywords: GRACE, Terrestrial Water Storage, GLDAS, Hydrologic Simulation

\section{Introduction}

GRACE (Gravity Recovery And Climate Experiment), twin satellites launched by NASA in 2002, measures minute variations in Earth's gravity field. A gravity field map obtained by GRACE shows how the Earth's mass varies from place to place. Therefore, by converting the gravitational field data into mass data, information on the distribution of water across the Earth's surface can be obtained [1].

Numerous studies have been conducted in the fields of geodesy, glaciology, hydrology, oceanography and solid Earth sciences, utilizing the data provided by GRACE. In the water resources engineering, studies mainly focus on the understanding of water relocation (e.g., on the basin scale estimation of evapotranspiration [2]; for the estimation of groundwater storage changes $[3,4])$, and the improvement in the estimation accuracy $[5,6]$. GRACE's ability to detect water storage changes at varied spatial scales over different parts of the globe has been demonstrated: Some examples include the Congo River Basin [7], India [8], East African lakes [9], California
Central Valley [10] and Turkey [11].

Lee et al. [12] was the first to attempt to check the applicability of the GRACE-based method to the water resources research of the Korean Peninsula. In their study, terrestrial water storage change (TWSC) was estimated and compared to the value calculated from a water balance analysis. Hydrogeologic data from GLDAS (Global Land Data Assimilation System) [13] and WAMIS (Water Management Information System) [14] were used for the analysis. Except for relatively wide discrepancies in the rainy season, the GRACE-based TWSC estimates showed a good agreement with the ones from the water balance analysis, suggesting a high potential of the GRACE-based technique.

In this study, the accuracy issue of the GRACE-based TWSC in the rainy season is further investigated. Since the big cell size $\left(1^{\circ} \times 1^{\circ}\right)$ of GLDAS was considered to be one of the main sources of uncertainty in the water balance analysis, we replace the runoff data from GLDAS with ones from hydrologic simulation. By doing so, we expect 
detail hydrogeologic conditions of the basin are reflected and it will lead to the enhancement of the accuracy of the technique based on the gravitational field variation.

\section{Methodology}

GRACE measures the long wavelength component of the Earth's gravity at an altitude of about $500 \mathrm{~km}$. The GRACE Level-2 data are created after compensating the tidal effect, and the non-tidal effect resulting from the variability of atmosphere and ocean.

Since the change in the terrestrial water storage, which consists of surface water, soil moisture, groundwater, etc., will change the gravitational field, the monthly gravitational field data can be converted into the liquid water equivalent thickness [15]. TWSC can also be computed using a monthly basin-scale terrestrial water balance which can be approximated as follows

$$
\left[\frac{\Delta S}{\Delta t}\right]_{N}=\sum_{N-1}^{N} P-\sum_{N-1}^{N} R-\sum_{N-1}^{N} E
$$

Where, $\mathrm{S}$ is the TWS, $\mathrm{t}$ is time, $\mathrm{N}$ represents month, $\mathrm{P}$ is precipitation, $\mathrm{R}$ is the net surface/subsurface runoff, and $\mathrm{E}$ is evapotranspiration.

Lee et al. [12] estimated the TWSC of the Korean Peninsula using land-based WAMIS data for precipitation and evapotranspiration, along with GLDAS data for runoff [13]. GLDAS provides meteorological satellite observation data such as precipitation, runoff, snow water equivalent, soil moisture, etc. at the grid interval of $1^{\circ} \times 1^{\circ}(111.1 \mathrm{~km}$ $\times 88.8 \mathrm{~km}$ ) which is the same as GRACE (Fig. 1). The mean TWSC of the Korean Peninsula was estimated to be $0.986 \mathrm{~cm} /$ month during the period of 2002 2010.

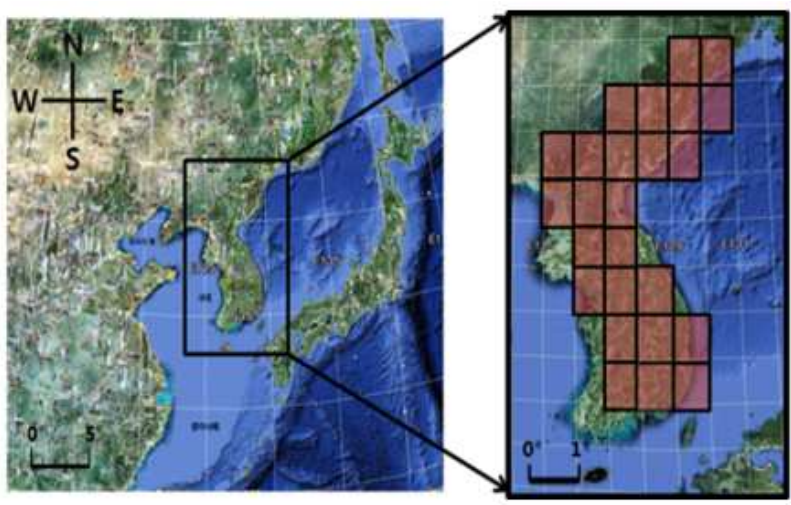

Figure 1. Cells for the Korean Peninsula from GRACE Tellus [12].

In order to reflect the geomorphological and hydrological characteristics in detail, here we substitute the runoff data from GLDAS with simulated ones from a hydrological model, HEC-HMS [16]. Our objective is to compare three different approaches; GRACE-based, Land/GLDAS-based, and Land/Simulation-based technique in estimating the TWSC (Fig. 2). Table 1 shows the spatial resolution and sources of hydrologic components used in different approaches.

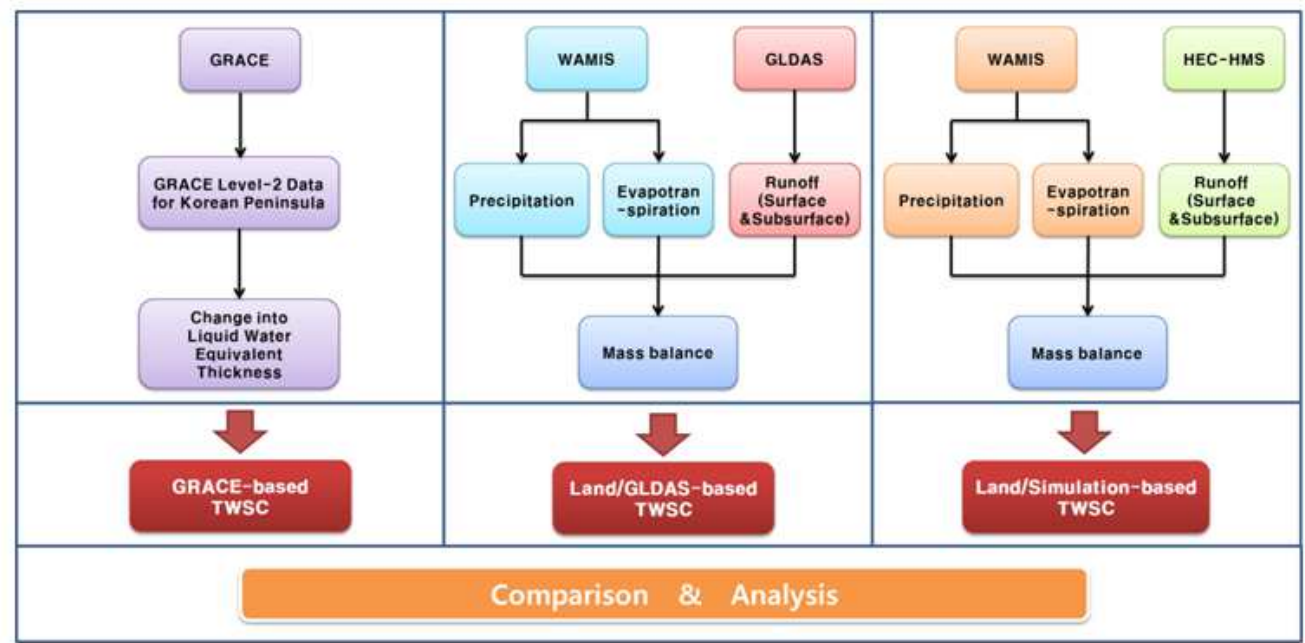

Figure 2. Three Different Approaches of the Study.

Table 1. Spatial Resolution and Sources of Hydrologic Components.

\begin{tabular}{|c|c|c|c|c|}
\hline Hydrologic Component & Spatial Extent & Spatial Resolution & Time Span & Source \\
\hline $\begin{array}{l}\text { Precipitation } \\
\text { Evapotranspiration }\end{array}$ & $126^{\circ} \mathrm{E} \sim 137^{\circ} \mathrm{E}$ & Local & Jul 15, 2003 & WAMIS \\
\hline $\begin{array}{l}\text { Runoff }^{1)} \\
\text { (surface \& subsurface) }\end{array}$ & & $1^{\circ} \times 1^{\circ}$ & $\sim$ & GLDAS \\
\hline $\begin{array}{l}\text { Runoff }^{2)} \\
\text { (surface \& subsurface) }\end{array}$ & $37^{\circ} \mathrm{N} \sim 38^{\circ} \mathrm{N}$ & Local & Aug 14, 2003 & HEC-HMS \\
\hline
\end{tabular}

1) Land/GLDAS-based approach, 2) Land/Simulation-based approach 


\section{Hydrologic Simulation}

\subsection{Study Area}

The study area is Seoul/Gyeonggi province of which the basic information needed for hydrologic analysis is quantitatively and qualitatively superior to other areas (Fig. 3(a)). The area consists of four basins, (A) Imjin River Basin, (B) Han River Basin, (C) Ganghwa Basin, and (D)
Banwol River Basin (Fig. 3(b)). High rate of urbanization of this area results in the high ratio of impervious area, which leads to intensified runoff concentration during the rainfall.

Geomorphological data were obtained from the digital maps provided by National Geographic Information Institute (NGII) [16], and hydrogeological data such as precipitation, river stage, soil and land use were provided by WAMIS [17].

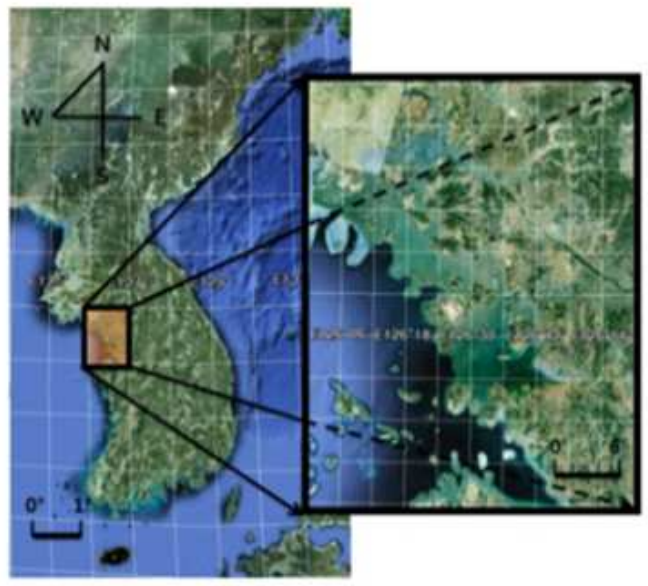

(a)

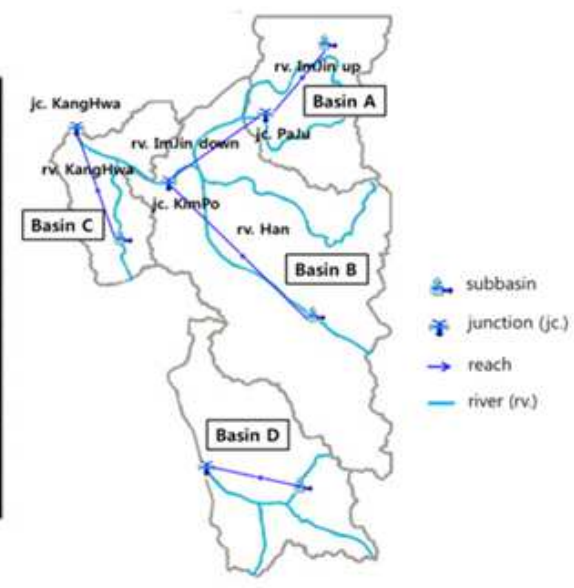

(b)

Figure 3. Study Area and Four Basins.

Table 2. Model Parameters

\begin{tabular}{|c|c|c|c|c|c|c|}
\hline & & Basin A & Basin B & Basin C & Basin D & Remark \\
\hline & Area $\left(\mathrm{km}^{2}\right)$ & 461.8 & 734.6 & 322.8 & 628.3 & \multirow{7}{*}{$\begin{array}{l}\text { NRCS Curve } \\
\text { Number Method }\end{array}$} \\
\hline Basin & Average Slope (\%) & 2.89 & 2.07 & 0.59 & 2.08 & \\
\hline \multirow[t]{2}{*}{ Information } & Main River Element & Imjin & Han & Seokjeong & Banwol & \\
\hline & Channel Length(km) & 29.89 & 74.73 & 14.27 & 31.98 & \\
\hline Initial & $I_{a}(\mathrm{~mm})$ & 8.13 & 10.85 & 13.34 & 10.04 & \\
\hline Abstraction & $\mathrm{CN}(-)$ & 86.2 & 82.4 & 79.2 & 83.5 & \\
\hline (AMC-III) & Impervious Area (\%) & 24.99 & 29.08 & 6.19 & 33.43 & \\
\hline \multirow{2}{*}{$\begin{array}{l}\text { Unit } \\
\text { Hydrograph }\end{array}$} & $T_{c}(\mathrm{hr})$ & $\begin{array}{l}2.37 \\
(1.01)^{*}\end{array}$ & $\begin{array}{l}5.93 \\
(8.96)\end{array}$ & 1.32 & 2.54 & \multirow{2}{*}{$\begin{array}{l}\text { Clark Unit } \\
\text { Hydrograph }\end{array}$} \\
\hline & $\mathrm{K}(\mathrm{hr})$ & $\begin{array}{l}2.56 \\
(1.09)\end{array}$ & $\begin{array}{l}4.90 \\
(7.42)\end{array}$ & 1.68 & 4.00 & \\
\hline \multirow{3}{*}{ Baseflow } & Initial Runoff( $\left(\mathrm{m}^{3} / \mathrm{s} / \mathrm{km}^{2}\right)$ & 0.11 & 0.11 & 0.11 & 0.11 & \multirow{3}{*}{$\begin{array}{l}\text { Exponential } \\
\text { Recession }^{3)}\end{array}$} \\
\hline & $\mathrm{R}(-)$ & 0.844 & 0.815 & 0.551 & 0.779 & \\
\hline & Peak Rate (-) & $\begin{array}{l}0.035 \\
(0.080)\end{array}$ & $\begin{array}{l}0.035 \\
(0.036)\end{array}$ & 0.035 & 0.035 & \\
\hline \multirow{3}{*}{$\begin{array}{l}\text { Stream } \\
\text { Routing }\end{array}$} & K (hr) & $\begin{array}{l}\text { up: } 5.887 \\
\text { Down: } 1.427\end{array}$ & 4.902 & 5.922 & 4.001 & \multirow{3}{*}{$\begin{array}{l}\text { Muskingum } \\
\text { Method }^{4)}\end{array}$} \\
\hline & X (-) & 0.2 & 0.2 & 0.2 & 0.2 & \\
\hline & NSTPS & 1 & 1 & 2 & 2 & \\
\hline
\end{tabular}

1) $I_{a}=0.2 S, S=\frac{25400}{C N}-254$ ( $I_{a}$ : Initial abstraction, $S$ : Potential maximum retention of rainfall)

2) $\quad T_{c}=0.2778 L / V$ ( $T_{c}$ : Time of concentration, $L$ : Channel length, $V:$ Mean velocity), $K=\frac{T_{C}}{1.46-0.0867 \frac{L^{2}}{A}}$ (K: Storage constant, $L:$ Channel length, $A$ : Basin area)

3) $\quad R=e^{-1 / K}(R:$ Recession constant, $K$ : Storage constant)

4) $K=L / V_{w}$ (K: Travel time, $L$ : Distant, $V_{w}$ : Flood wave velocity), $x$ : weighting factor, NSTPS: Number of routing steps

$*(\quad)$ is the optimized value.

\subsection{Model Parameters}

Hydrologic simulation using HEC-HMS requires a series of selection for process-describing methods and related model parameters. To represent the initial abstraction, for example, the NRCS Curve number method was used. Since the simulation period corresponds to the rainy spell in 
summer (July $15 \sim$ August 14, 2003), the soil condition was set to be AMC-III. The CN-value was calculated from soiland land use maps. As for the unit hydrograph, the Clark unit hydrograph model was used. It is known to be suitable for a small/medium basin and widely applied to urban and natural basins. For baseflow calculation, the exponential recession model was used. The Muskingum method was used for stream routing. The main parameters and their initial values required for the analysis are shown in Table 2.
The parameter optimization program provided in HEC-HMS was used to reduce the difference between simulated and observed runoff. Optimized values are shown in the parenthesis of Table 2. The result of hydrologic analysis at Kimpo Junction is shown in Fig. 4. It shows the improved performance when optimized parameters are used in the simulation. The error after the optimization turned out to be $29 \%$ lesser than before.

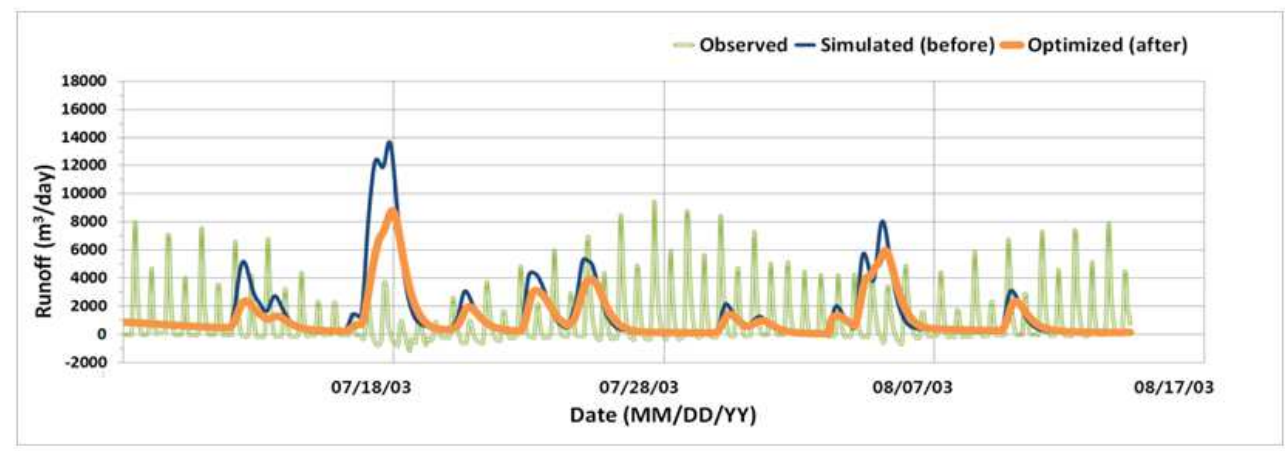

Figure 4. Runoff at Kimpo Junction Before \& After Parameter Optimization.

\section{Results and Discussion}

The runoff obtained from optimized hydrological simulation is substituted into the water balance (Eq. (1)) in order to calculate the Land/Simulation-based TWSC. The effective precipitation of each basin is calculated by subtracting the loss from the total precipitation. The mean precipitation $(\mathrm{P})$ over the entire region estimated from the Thiessen Polygon method is $32.89 \mathrm{~cm} /$ month.

$$
\mathrm{P}=\sum_{i} \frac{A_{i} P_{i}}{A_{T}}
$$

Where, $A_{i}$ is the area of each basin, $P_{i}$ is the effective precipitation of each basin, $A_{T}$ is the total area. The depth of runoff $(\mathrm{R})$ calculated by dividing the runoff by the total basin area $\left(8,758.9 \mathrm{~km}^{2}\right)$ is $18.91 \mathrm{~cm} / \mathrm{month}$, and the depth of the evapotranspiration (E) is $8.79 \mathrm{~cm} /$ month. Now the Land/Simulation-based TWSC is obtained by substituting P, $\mathrm{R}$ and $\mathrm{E}$ values into Eq. (1): $5.19 \mathrm{~cm} /$ month.

Lee et al. [12] found that the GRACE-based TWSC of the study basin from July 15 to Aug 14, 2003 was 1.45 $\mathrm{cm} /$ month, while the Land/GLDAS-based TWSC obtained from the water balance using the GLDAS runoff data was $3.96 \mathrm{~cm} /$ month. Comparing these values with the Land/Simulation-based TWSC obtained above (5.19 $\mathrm{cm} / \mathrm{month}$ ), we find that the GRACE-based, and the Land/GLDAS-based approaches underestimate the TWSC during the wet season (Table 3 ).

Table 3. Comparison of Three Different Approaches.

\begin{tabular}{l|ccc}
\hline & $\begin{array}{c}\text { GRACE- } \\
\text { based }\end{array}$ & $\begin{array}{c}\text { Land/GLDAS- } \\
\text { based }\end{array}$ & $\begin{array}{c}\text { Land/Simulation- } \\
\text { based }\end{array}$ \\
\hline $\begin{array}{l}\text { TWSC } \\
\text { (cm/month) }\end{array}$ & 1.45 & 3.96 & 5.19 \\
\hline
\end{tabular}

It is noteworthy that while the GRACE- and the Land/GLDAS-based TWSCs are relatively straightforward to obtain, the degree of complexity in calculating the Land/Simulation-based TWSC is much higher. Therefore, if an appropriate correction factor is introduced to the GRACE-based TWSC (3.58 for Land/Simulation-based estimates and 2.73 for Land/GLDAS-based, in the case), TWSC can be calculated utilizing the gravitational data in a much simpler way than traditional methods. When correction factors corresponding to various weather patterns for the basin of interest become available, the usefulness of the GRACE-based approach can be greatly improved.

\section{Conclusion}

Reliable estimation of terrestrial water storage is important for the sustainable management of water resources. The GRACE-based approach using the gravitational field variation has proven its effectiveness in estimating TWS changes. The largeness in spatial and temporal scales of GRACE-based estimation, however, limits its applicability to smaller areas or time-varying weather conditions.

This work attempted to check the accuracy of three different methods to estimate TWSC for a relatively small basin during the rainy season. TWSC estimated from direct GRACE-approach was compared with the estimates from the water balance with two runoff values: One from GLDAS and the other from hydrologic simulation.

As a result, we found that the GRACE-, and the Land/GLDAS-based approaches underestimate the TWSC during the wet season, compared to the Land/Simulation approach. It suggests that we can save a lot of time, cost 
and resources required for hydrologic analysis if we have appropriate correction factors to multiply since the GRACE-based TWSC is relatively easy and less costly to obtain. When enough information is accumulated for various basins with diverse weather conditions, GRACE can be a useful tool to estimate TWSC with high accuracy and effectiveness.

\section{Acknowledgements}

This research was sponsored by the NRF (National Research Foundation of Korea) under the contract number 2013-052502.

\section{References}

[1] B. D. Tapley, S. Bettadpur, J. C. Ries, P. F. Thompson, and M. M. Watkins, "GRACE measurements of mass variability in the earth system," Science, 2004, vol. 305, pp. 503-505.

[2] M. Rodell, J. S. Famiglietti, J. Chen, S. I. Seneviratne, P. Viterbo, and S. Holl, "Basin scale estimates of evapotranspiration using GRACE and other observations,"Geophys. Res. Lett., 2004, vol. 31, pp. L20504.

[3] M. Rodell, J. Chen, H. Kato, J. S. Famiglietti, J. Nigro, and C. R. Wilson, "Estimating groundwater storage changes in the Mississippi River Basin (USA) using GRACE," Hydrogeol. J., 2007, vol. 15, pp. 159-166.

[4] P. J. F. Yeh, S. C. Swenson, J. S. Famiglietti, and M. Rodell, "Remote sensing of groundwater storage changes in Illinois using the Gravity Recovery and Climate Experiment (GRACE)," Water Resour. Res., 2006, vol. 42, pp. W12203.

[5] S. Swenson, J. Wahr, and P. C. D. Milly, "Estimated accuracies of regional water storage variations inferred from the Gravity Recovery and Climate Experiment (GRACE),'WaterResour. Res., 2003, vol. 39, pp. 1223.

[6] J. Wahr, S. Swenson, I. Velicogna, "Accuracy of GRACE mass estimates,"Geophys. Res. Lett., 2006, vol. 33, pp. L06401.
[7] J.W. Crowely, J.X. Mitrovica, R.C. Bailey, M.E. Tamisiea, and J.L. Davis, "Land water storage within the Congo Basin inferred from GRACE satellite gravity data,"Geophys. Res. Lett., 2006, vol. 33, pp. L19402.

[8] M. Rodell, I. Velicogna, and J.S. Famiglietti, "Satellite-based estimates of groundwater depletion in India," Nature, 2009, vol. 460, pp. 999-1002.

[9] M. Becker, W. LLovel, A. Cazenave, A. Guntner, and J. F. Cretaux, "Recent hydrological behavior of the East African great lakes region inferred from GRACE, satellite altimetry and rainfall observations," C. R. Geosci., 2010, vol. 342, pp. 223-233.

[10] B. R. Sacanlon, L. Longuevergne, and D. Long, "Ground referencing GRACE satellite estimates of groundwater storage changes in the California Central Valley, USA,'WaterResour. Res., 2012, vol. 48, pp. W04520.

[11] O. Lenk, "Satellite based estimates of terrestrial water storage variations in Turkey," J. Geodyn., 2012, vol. 67, pp. 106-110.

[12] S.-I. Lee, J. S. Kim, and S. K. Lee, "Estimation of average terrestrial water storage changes in the Korean Peninsula using GRACE satellite gravity data," J. Korean Water Resour. Asso., 2010, vol. 45, pp. 805-814.

[13] NASA GES DISC, 2012, Available online at: http://daac. gsfc.nasa.gov/.

[14] Water Management Information System (WAMIS). 2012. Available online at: http://www.wamis.go.kr/.

[15] T. H. Syed, J. S. Famiglietti, M. Rodell, J. Chen, and C. R. Wilson, "Analysis of terrestrial water storage changes from GRACE and GLDAS," Water Resour. Res., 2008, vol. 44, pp. W02433.

[16] U.S. Army of Civil Engineers, HEC-HMS Manual, 2012.

[17] National Geographic Information Institute (NGII), 2012, Available online at: http://www.ngii.go.kr/. 